\title{
Corrections to Øien, Cicchetti, and Nordahl-Hansen's (2018) “Gender Dysphoria, Sexuality and Autism Spectrum Disorder: A Systematic Map Review"
}

\author{
Kenneth J. Zucker ${ }^{1}$ (I) . Doug P. VanderLaan ${ }^{2}$
}

Published online: 15 September 2018

(c) Springer Science+Business Media, LLC, part of Springer Nature 2018

Øien, Cicchetti, and Nordahl-Hansen (2018) have provided a very nice "map review" on the relation between gender dysphoria, sexuality, and autism. It will serve as an excellent overview for future research initiatives. There are, however, two elements of the review that require clarification/ correction.

First, regarding the DSM-5 diagnosis of gender dysphoria (GD), Øien et al. wrote: "GID [Gender Identity Disorder in the DSM-IV-TR] had been classified on the basis of crossgender identification together with distress caused to the person by her/his biological sex, while GD does not require the person to be distressed by the disparity." Technically, this is correct. In the DSM-5, Criterion B reads: "The condition is associated with clinically significant distress or impairment in social, school [for adolescents and adults, occupational], or other important areas of functioning" (American Psychiatric Association 2013, pp. 452-453, emphasis added). However, this is no different from Criterion D in the DSM-IV-TR: "The disturbance causes clinically significant distress or impairment in social, occupational, or other important areas of functioning" (American Psychiatric Association 2000, p. 581, emphasis added). Thus, in both the DSM-IV-TR and the DSM-5, distress and/or impairment are required to give the diagnosis.

Second, regarding the VanderLaan et al. (2015) study noted in Table 2, there were a couple of errors. Regarding the number of cases and gender at birth, the correct entry should have been limited to the 534 gender-referred children (439 male, 95 female). In the Control group column, it should have been 419 siblings ( 241 male, 178 female). In

Kenneth J. Zucker

ken.zucker@utoronto.ca

1 Department of Psychiatry, University of Toronto, Toronto, ON M5T 1R8, Canada

2 Department of Psychology, University of Toronto Mississauga, Mississauga, ON, Canada addition, the Control group column should have included 582 referred males, 582 non-referred males, 619 referred males, and 619 non-referred females from the Child Behavior Checklist standardization sample (Achenbach 1991).

Author Contributions KJZ and DPV have contributed equally to this Letter.

\section{Compliance with Ethical Standards}

Conflict of interest The authors declare that they have no conflict of interest.

Ethical Approval This Letter does not contain any studies with human participants or animals performed by the authors.

\section{References}

Achenbach, T. M. (1991). Manual for the Child Behavior Checklist/4-18 and 1991 Profile. Burlington: University of Vermont Department of Psychiatry.

American Psychiatric Association. (2000). Diagnostic and statistical manual of mental disorders (4th ed., text rev). Washington, DC: American Psychiatric Association.

American Psychiatric Association. (2013). Diagnostic and statistical manual of mental disorders (5th edn.). Arlington: American Psychiatric Press.

Øien, R. A., Cicchetti, D. V., \& Nordahl-Hansen, A. (2018). Gender dysphoria, sexuality and autism spectrum disorders: A systematic map review. Journal of Autism and Developmental Disorders. https://doi.org/10.1007/s10803-018-3686-7.

VanderLaan, D. P., Postema, L., Wood, H., Singh, D., Fantus, S., Hyun, J., et al. (2015). Do children with gender dysphoria have intense/ obsessional interests? Journal of Sex Research, 52, 213-219. 